\title{
Busca e recuperação da informação científica na web: comportamento informacional de profissionais da informação ${ }^{1}$
}

\author{
Search and retrieval of scientific information on the web: the information behavior of \\ information professionals
}

\begin{abstract}
Rafaela Boeira Giordano
Mestre e Doutoranda em Ciência da Informação pelo Instituto Brasileiro de Ciência e Tecnologia - IBICT/UFRJ

E-mail: rafaelagiordano@gmail.com

Jorge Calmon de Almeida Biolchini

Doutor em Ciência da Informação pelo Instituto Brasileiro de Ciência e Tecnologia - IBICT/UFRJ.

Professor Titular do Programa de Pós-Graduação em Ciência da Informação do IBICT/UFRJ

E-mail: jorge.biolchini@gmail.com
\end{abstract}

\section{Resumo}

Avanços tecnológicos, crescimento exponencial de conteúdos na web, aumento da busca on-line por informação especializada alteraram o comportamento de cientistas no acesso à informação. Nesse contexto, revela-se de importância capital a competência em informação. Por meio deste estudo, objetiva-se analisar o comportamento informacional do cientista da informação no processo de busca e recuperação na web, evidenciando ações adotadas, estratégias, formulações, pontos críticos, decisões tomadas, resultados obtidos e grau de satisfação. Para isso, realizou-se pesquisa exploratória sobre o comportamento de pós-graduandos na busca de informação científica na web. Utilizou-se questionário e entrevista elaborados a partir da técnica do incidente crítico. A aprendizagem informal constitui o modo principal para adquirir habilidades em busca e recuperação da informação. A utilização de mecanismo genérico de busca, sem o emprego de recursos avançados, o baixo uso de operadores, o número reduzido de termos constituem estratégias de busca predominantes. Resultados apontam a necessidade de fomentar o aprimoramento da competência em informação a fim de contribuir na qualidade do processo de busca e recuperação entre cientistas da informação.

Palavras-chave: Recuperação da informação. Recuperação da informação na web. Competência em informação. Informação científica. Comportamento informacional.

\begin{abstract}
Technological advances, exponential growth of web content and increase of online search for specialized information contributed to changes on the information accessing behavior of scientists. In this context, the capital importance of information literacy was revealed. The study aimed to analyze the information behavior of information scientists during the search and retrieval process on internet, highlighting actions, strategies, formulations, critical points, decisions taken, and satisfaction evaluation. Therefore, the study constitutes an exploratory investigation into the behavior of post-graduate students while searching for scientific information on the web. Questionnaire and interview based on the critical incident technique were applied. Informal learning constitutes the main mode of skill acquisition in information search and retrieval. The use of a generic search engine without employing its advanced resources, few operators and reduced number of terms constitute the most common search strategies. Results point to the need of fostering information literacy improvement in order to contribute to the search and retrieval process quality among information scientists.
\end{abstract}

Keywords: Information retrieval. Information retrieval on the web. Information literacy. Scientific information. Information behavior.

\footnotetext{
${ }^{1}$ O presente artigo é uma versão com pequenas alterações do trabalho apresentado no XII Encontro Nacional de Pesquisa em Ciência da Informação, 2011.
}

InCID: R. Ci. Inf. e Doc., Ribeirão Preto, v. 3, n.1, p. 125-145, jan./jun. 2012. 


\section{Introdução}

O comportamento dos cientistas no processo de construção do conhecimento tem sido alterado significativamente por transformações contemporâneas relacionadas ao acesso à informação. Nas últimas décadas, o avanço de tecnologias de informação e comunicação, essenciais na consolidação da chamada sociedade da informação, levou ao desenvolvimento de mecanismos e ferramentas que alteraram a maneira como a informação vinha sendo acessada. Manejada inicialmente apenas por especialistas, a informação passou a ser buscada e recuperada por diferentes usuários finais - primeiro em sistemas informatizados de recuperação da informação; mais tarde, via internet e world wide web.

A web - termo metafórico pelo qual a interface humano-máquina da rede mundial de computadores tornou-se conhecida - criou na sociedade conectada computacionalmente a possibilidade, bem como a expectativa, de acesso facilitado e rápido a diferentes tipos de informação. Não há como negar que a web é hoje o maior acervo de informações do mundo e encontra-se em crescimento exponencial. Nesse cenário, utilizar o conteúdo existente no ciberespaço de maneira competente, a fim de atender a diferentes tipos de necessidades informacionais, apresenta-se como um dos grandes desafios contemporâneos.

Em pouco mais de uma década, a web passou a fazer parte do cotidiano de indivíduos inseridos nos mais diferentes contextos, inclusive, desde a sua origem, o científico. Para esse público em especial, a rede abriga artigos acadêmicos, revistas especializadas, bases de dados de temas específicos, teses, dissertações e acervos de bibliotecas digitais, entre outros materiais - normalmente disponibilizados em formato digital e prontos para serem salvos no computador do usuário.

Resolvida a questão da acessibilidade à informação de maneira satisfatória, em aspectos como rapidez, localização e abrangência de conteúdos, surgem outras facetas, como relevância, especificidade e utilidade dos elementos recuperados, determinados de acordo com a necessidade informacional do indivíduo. O expressivo e crescente volume de conteúdos disponibilizados na web contribui para dificultar a ampliação do grau de especificidade na recuperação da informação, elemento-chave para garantir sua relevância informacional e sua utilidade no desenvolvimento da produção científica.

Esse fenômeno pode afetar áreas em que tanto a diversidade de sua temática quanto a amplitude de sua interdisciplinaridade apresentam-se em grau significativo, como na Ciência 
da Informação. Sendo assim, identificar o comportamento informacional de cientistas da informação para o desenvolvimento de projetos científicos pode contribuir para o aprimoramento dos processos da própria produção científica no campo da Ciência da Informação, fornecendo subsídios que podem colaborar com o incremento da eficiência e da efetividade dos mesmos.

Por meio do presente estudo pretendeu-se analisar o processo de busca e recuperação da informação científica na web adotado por pós-graduandos em Ciência da Informação. Na pesquisa, elaborada com base na abordagem metodológica do incidente crítico, mapeou-se o percurso de ações adotado pela população-alvo durante diferentes etapas do processo, identificando-se estratégias, formulações e decisões tomadas. Os resultados permitiram elaborar análises de pontos críticos desse processo, assim como identificar habilidades e competências necessárias na condução das atividades de busca e recuperação da informação para fins de produção acadêmica.

\section{Busca e recuperação da informação}

Processos de busca e recuperação da informação são desencadeados a partir da necessidade informacional de um indivíduo. A maneira como essa demanda será expressada na interface dos sistemas de informação mecanizados é elemento-chave na determinação dos resultados passíveis de serem obtidos. A recuperação da informação, como resume Saracevic (MOSTAFA, 2010, p. 162), trata sobre o que pode ser feito para acessar, de maneira rápida e efetiva, a informação inserida em determinado repositório - neste caso, a web.

Estudos na área da busca e recuperação da informação evoluíram de acordo com as necessidades apresentadas ao longo de décadas. Alterações significativas foram percebidas com o surgimento da web, em princípios dos anos 1990, assim como em decorrência do crescimento desenfreado, tanto do uso quanto do tamanho da rede. De interação estática e com escassez de informação na fase inicial, a web transformou-se progressivamente no veículo preferido de usuários - com diferentes perfis e níveis de conhecimentos - e local ideal para o armazenamento de todos os tipos de materiais, sejam vídeos, textos, músicas, filmes ou imagens. Acrescente-se a isso, o caráter interativo e dinâmico da rede, além do fato de ser hoje utilizada por aproximadamente dois bilhões de pessoas ao redor do mundo. 
Com os avanços tecnológicos, a disseminação do uso da web e as melhorias constantes nos mecanismos de busca, tarefas normalmente desempenhadas por profissionais habilitados passaram a ser executadas também pelos chamados usuários finais. Incluídos nesse grupo estão pesquisadores e cientistas. Como afirmam os pesquisadores Lawrence e Giles (1998, p. 98), a recuperação de informação científica e de literatura especializada, antes dominada por bibliotecários, tornou-se disponível diretamente para os cientistas. Saracevic (MOSTAFA, 2010, p. 162) reforça essa idéia ao afirmar que buscar informação tornou-se ubíquo - todo mundo é buscador hoje em dia.

O processo de recuperação da informação, tal qual foi cunhado por Calvin Mooers em 1951, engloba os aspectos intelectuais de descrição da informação e suas especificidades para a busca, além de quaisquer sistemas, técnicas ou máquinas que sejam empregadas para realizar esta operação (MOOERS, 1951 apud SARACEVIC, 1996, p. 44). Lesk (1995, p. 4) aponta que a experimentação das primeiras décadas levou ao surgimento de medidas de avaliação: revocação (recall), referindo-se à fração de documentos recuperados em relação ao total existente, e precisão, dizendo respeito à fração de documentos recuperados que são relevantes. As duas medidas funcionam satisfatoriamente em sistemas fechados e com número conhecido de itens. Porém, Yang (2005, p. 33) ressalta que em sistemas web, as medidas convencionais mostram-se inadequadas, pois sem se saber o tamanho do acervo, torna-se impossível precisar quanto dele foi recuperado ou mesmo quanto é relevante.

Outro aspecto observado por Yang (2005, p. 33) - ressaltando que buscar informação na web é algo diverso em caráter e imprevisível por natureza - diz respeito especialmente à diversidade de usuários, com seus diferentes backgrounds e motivados por tipos variados de necessidade informacional. Sobre os "novos" usuários de sistemas de recuperação, Manning, Raghavan e Schütze (2009, p. 432) observaram que na tradicional recuperação da informação usuários eram tipicamente profissionais com treinamento sobre como criar consultas para uma coleção cujo estilo e estrutura eles conheciam bem; já os usuários da web tendem a não saber - ou se importar - com a heterogeneidade do conteúdo e a sintaxe das linguagens de criação de consulta. "Ademais, nem é papel de uma plataforma como a web exigir esse tipo de conhecimento de bilhões de pessoas." (MANNING; RAGAVHAN; SCHÜTZE, 2009, p. 432)

A disponibilidade ilimitada de informações oferecida pela web, associada à capacidade cada vez mais alta de recuperação dos mecanismos de busca, possibilita até mesmo imaginar que este seria o cenário perfeito para atender às mais variadas necessidades de informação dos 
indivíduos. Paradoxalmente, porém, como aponta Dudziak (2003, p. 23), justamente esses dois fatores contribuem para o aparecimento de barreiras ao acesso. Ao realizar uma busca sem conhecer ou sem utilizar de maneira apropriada os mecanismos de filtragem disponíveis, o indivíduo depara-se com número tão volumoso de fontes, que se torna impossível analisar os resultados de forma rápida e fácil como se imaginava e se propunha poder.

É nesse cenário que se evidencia a competência em informação (information literacy), área de estudos, de acordo com definição de Hatschbach (2002, p. 14), que trata das habilidades fundamentais para que o indivíduo obtenha sucesso na sociedade da informação e das habilidades aplicáveis a todas as situações de resolução de um problema ligado à necessidade de informação.

No que diz respeito à web, outras habilidades ganharam relevância a partir dos anos 1990, mais especificamente aquelas sobre entender a informação e - mais importante avaliá-la e integrá-la em múltiplos formatos fornecidos por um computador conectado a uma rede. Essa competência relacionada à informação digital é impossível sem avaliar as fontes ou colocá-la dentro de um contexto, como afirma Gilster em entrevista sobre competência digital (POOL, 1997, p. 6).

Para o autor, lidar com a informação encontrada na web é diferente de lidar com informações encontradas em livros, e por algumas razões. Primeiro, na web nem tudo é texto, pode haver vídeos, fotos, áudios. Segundo, a maneira como indivíduos encontram informação é diferente da maneira como nós usávamos cartões de referência em uma biblioteca. "Um computador multimídia conectado à internet permite que as pessoas realmente 'construam' informação de todos os lugares do mundo" (GILSTER apud POOL, 1997, p. 6). Terceiro, ser digitalmente capaz significa ser multidimensional e interativo.

Para Gilster, entrevistado por Brody e Swisher em 2010, competência digital envolve ser capaz de entender um problema em particular o suficiente para criar uma série de questionamentos que servirão de base para buscar mais informações sobre o problema ao consultar a web. Mais do que acessar a um conjunto estático de fontes, trabalha-se com uma biblioteca hipertextual que está sempre se expandindo. Uma pessoa letrada digitalmente aprende como criar uma provisão de informações que são sempre atualizadas quando surgem novas fontes. A natureza desse material demanda um letramento que está focado em hábitos fortes de pensamento crítico. 
De acordo com Gilster, pensamento crítico é a principal competência que um estudante deveria desenvolver ao buscar informações. Tais competências envolvem desde aprender a refinar as consultas até como usar mecanismos de busca para descobrir outras opiniões ou comentários sobre o assunto recuperado. Outra competência essencial é chamada pelo autor de knowledge assembly, em uma tradução livre "ajuntamento de conhecimento", ou seja, a capacidade de extrair informações de diferentes fontes e formatos, seja um texto, um vídeo ou um tópico em uma lista de discussão, conseguindo avaliar o valor e as limitações de cada elemento.

\section{Metodologia}

Para a realização deste estudo de caráter exploratório desenvolveu-se pesquisa de campo de natureza qualitativa, com elementos subsidiários para análises quantitativas. Foram utilizados dois instrumentos integrados, questionário e entrevista, ambos elaborados a partir da técnica do incidente crítico. Desenvolvida por Flanagan (1954), inicialmente no campo da Psicologia, a técnica do incidente crítico apresenta procedimentos para a coleta de observações diretas do comportamento humano, além de proporcionar informações sobre situações reais definidas - não teóricas ou hipotéticas. Tal técnica permite que os indivíduos pesquisados contribuam com informações baseadas em suas próprias experiências.

A pesquisa foi iniciada com aplicação de questionário, no qual os pós-graduandos relataram uma experiência de busca e recuperação da informação científica na web. Para esclarecimento de dúvidas - e em uma tentativa de diminuir o risco de esquecimento ou distorção de detalhes - optou-se pela complementação de informações por meio do uso de entrevista semiestruturada, alternativa para esclarecer aspectos obtidos através do primeiro instrumento de coleta de informações que não ficassem claros o suficiente.

A pesquisa de campo foi aplicada à população-alvo formada por pós-graduandos em Ciência da Informação, incluindo discentes tanto em nível de mestrado quanto de doutorado. Este grupo populacional constitui um "grupo natural", definido por Gaskell (2008, p. 69) como um grupo composto por pessoas que partilham um projeto comum, e que apresenta características como homogeneidade e compartilhamento de uma necessidade comum. Todos os integrantes são pós-graduandos, têm a informação como objeto de estudo e são especialistas em suas respectivas áreas de formação profissional. Além disso, ao trabalharem 
na produção de suas teses e dissertações, depararam-se com a necessidade de buscar informações para utilizá-las no desenvolvimento dos seus projetos.

Apesar de diferente na semântica, a natureza da informação buscada pelos pósgraduandos é semelhante na forma, ou seja, mestrandos e doutorados procuram por artigos acadêmicos, publicações em periódicos científicos, livros, citações etc. Como enumera Miller (2002), as principais necessidades informacionais de cientistas são: informação atual para manter-se atualizado sobre o campo em que estão inseridos; informação específica relacionada às tarefas desempenhadas; informações para criar marcos referenciais que constituam a base de projetos de pesquisa; e revisões de áreas relacionadas ou periféricas à pesquisa.

Tanto a aplicação do questionário quanto da entrevista complementar ocorreram durante seis semanas entre novembro e dezembro de 2010.

\section{Resultados}

Cinquenta e dois pós-graduandos participaram da pesquisa, representando $80 \%$ da população-alvo. Desses 52 participantes, 65\% frequentavam o mestrado e 35\%, o doutorado. Em consonância com a definição de Foskett (1980, p.48) para Ciência da Informação, “disciplina que surge de 'fertilização cruzada' de ideias", o levantamento dos campos de conhecimento, tanto entre mestrandos quanto entre doutorandos, apontou grande interdisciplinaridade da base de alunos, como se observa na Figura 1.

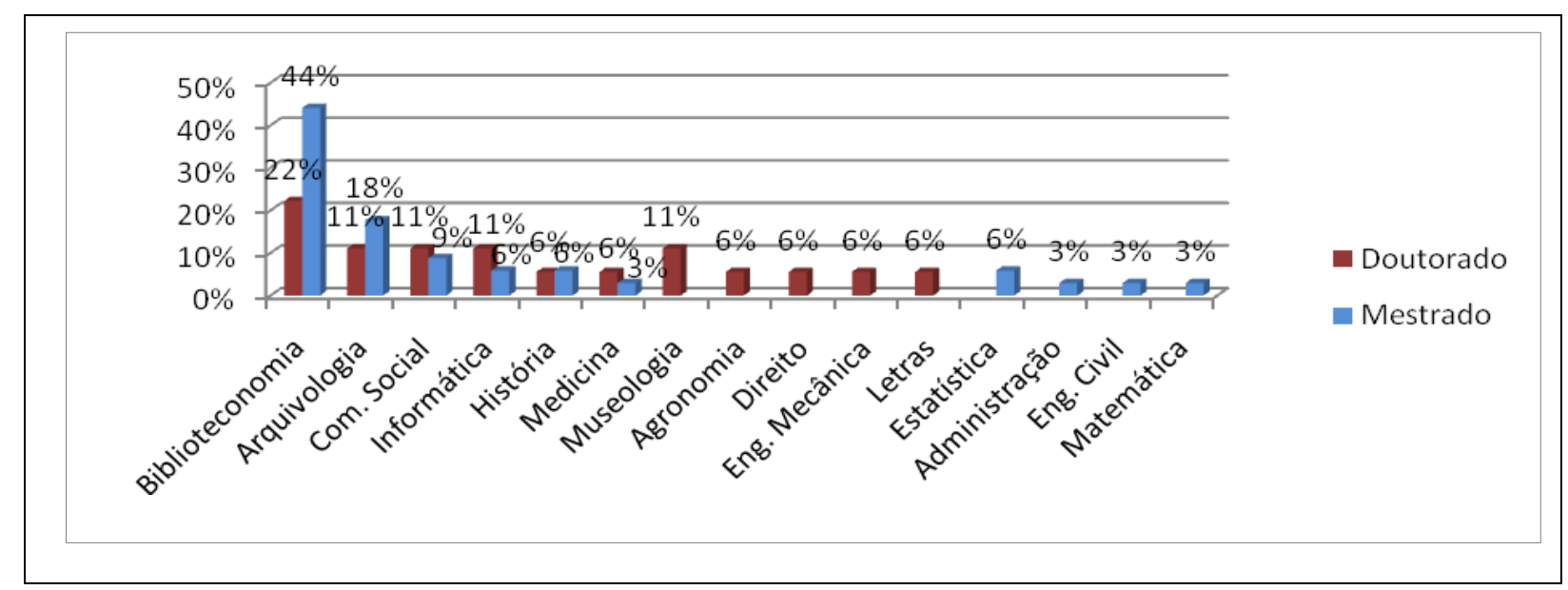

Figura 1 - Campos de origem dos pós-graduandos participantes da pesquisa de campo

Os mestrandos graduaram-se em seus respectivos cursos entre 1972 e 2007. Entre os doutorandos, o período de graduação estendeu-se de 1969 a 2006. 
Em relação às áreas de pesquisa, observa-se na Figura 2 em quais campos há maior concentração de estudos. A partir da nuvem de etiquetas, nota-se grande presença, em ambos os grupos, das Ciências Humanas e das Ciências Sociais Aplicadas. Por estarem relacionadas a disciplinas classicamente vinculadas à Ciência da Informação, nota-se presença destacada de campos como a Biblioteconomia, a Comunicação e a Ciência da Computação em ambos os níveis de pós-graduação.

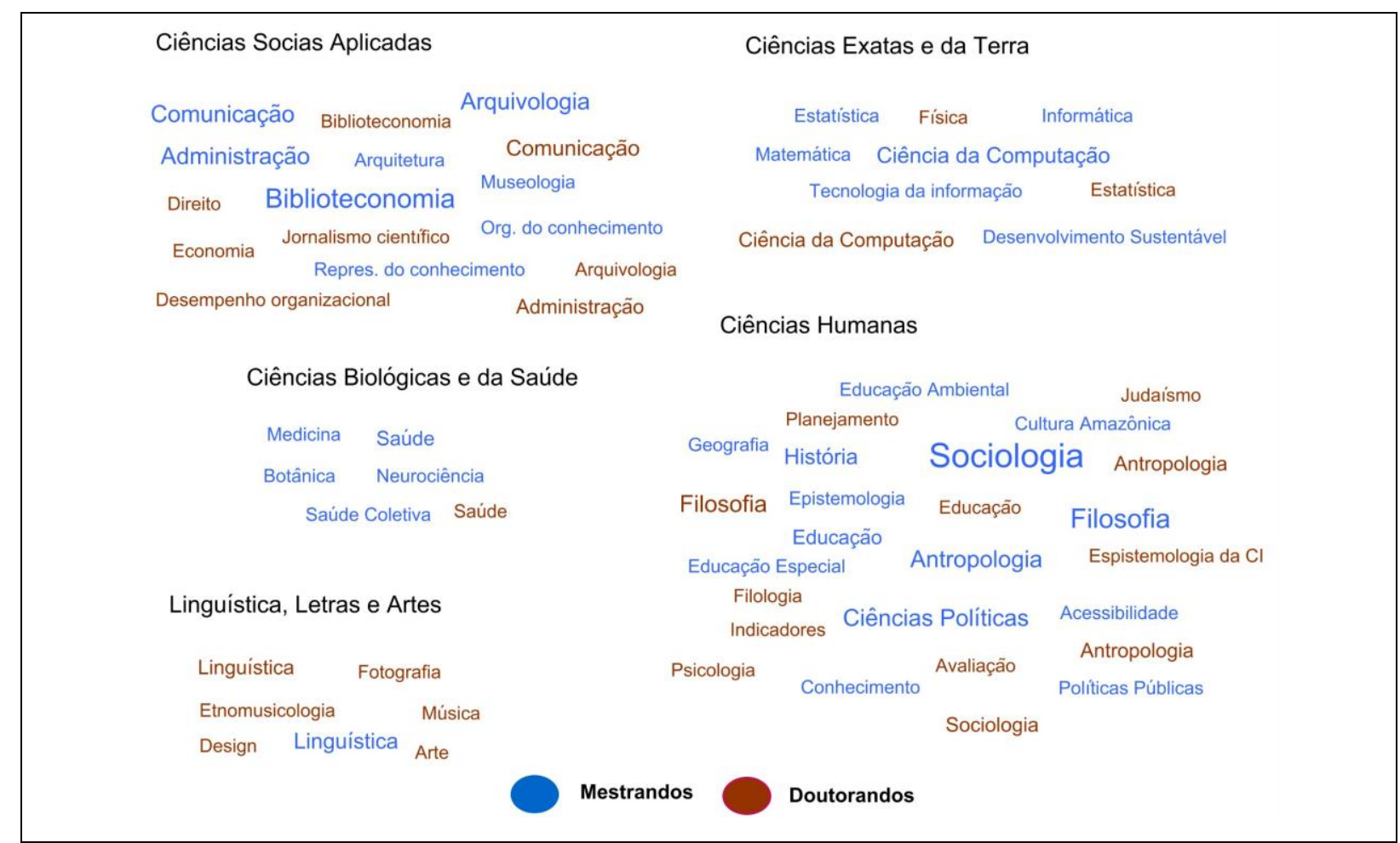

Figura 2 - Nuvem de etiquetas com campos e áreas do conhecimento inseridas nos projetos de dissertação e teses dos pós-graduandos participantes

O grupo caracteriza-se como homogêneo ao se abordar a maneira como adquiriu ou aperfeiçoou as habilidades de busca e recuperação na web. Praticamente $90 \%$ assinalaram ter desenvolvido conhecimentos neste quesito por experiência própria, aprendendo na prática. A segunda opção, escolhida por cerca de $45 \%$ do grupo, remete ao aprendizado com colegas, amigos, parentes e conhecidos. Esses dados indicam a forte predominância de modos informais de aquisição de conhecimento e de competência informacional. 


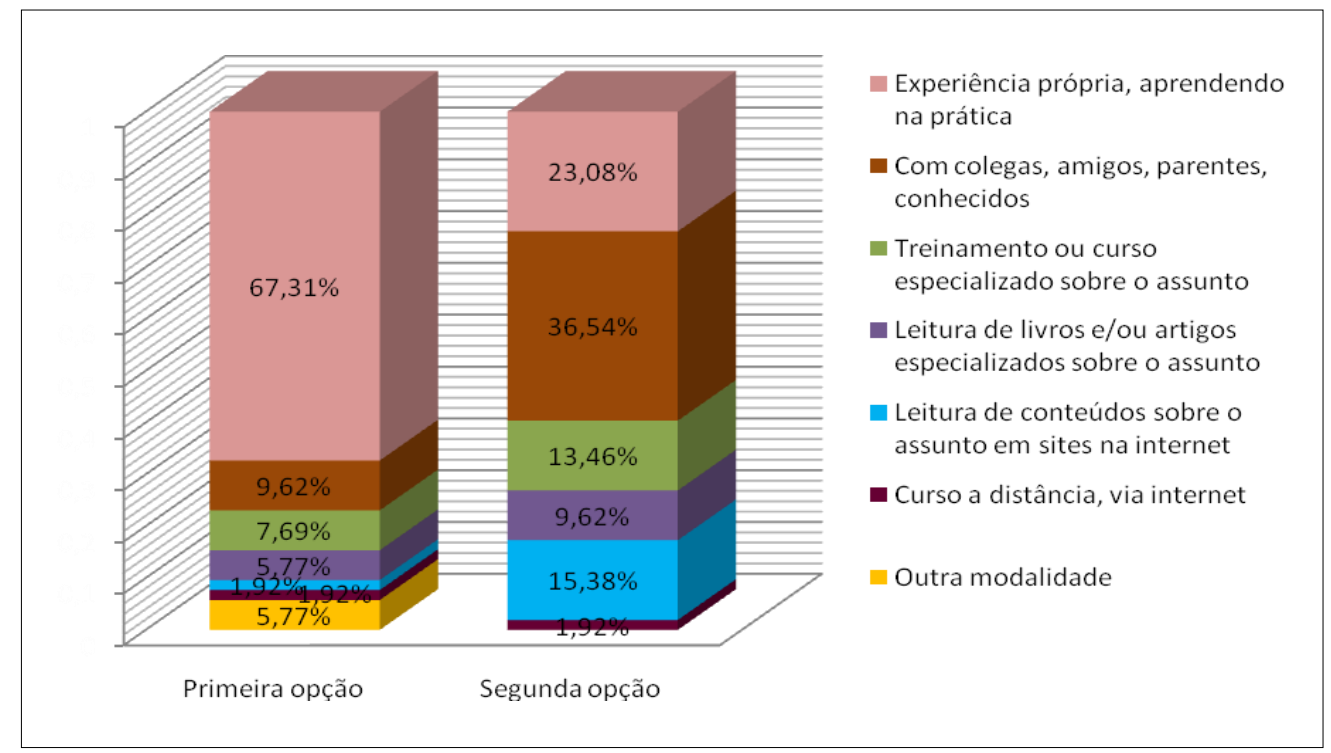

Figura 3 - Primeira e segunda opções por meio das quais pós-graduandos adquiriram conhecimento sobre busca e recuperação na web

Uma variação a esse comportamento ocorreu entre os pós-graduandos com formação em Biblioteconomia. Apenas 10,5\% escolheram a combinação apresentada acima, de caráter autodidata. Nas demais respostas dos bibliotecários, compreendendo 84,2\%, foram assinaladas opções relacionadas a cursos, treinamentos, disciplinas da graduação ou leitura de conteúdos sobre o tema. Infere-se que bibliotecários, por estarem inseridos em uma área que tradicionalmente trabalha com busca e recuperação da informação, vão além da formação autodidata ou do aprendizado realizado de maneira informal com conhecidos e colegas.

Ao responder como aprenderam a encontrar informações na web, os participantes encaixaram-se especialmente em dois perfis. $\mathrm{O}$ primeiro deles caracteriza-se pelo aprendizado autodidata e pelo método de tentativa e erro, ambos ocasionando demanda maior de tempo, e, consequente baixa eficiência de aprendizagem; ainda que, por se tratar de um ambiente virtual, a possibilidade de testar ampla gama de possibilidades poderia lhes trazer alguma vantagem na aquisição de conhecimento tácito, ainda que com maior dispêndio de tempo e de esforço. No segundo perfil estão inseridos os profissionais que se submeteram a algum tipo de treinamento, seja imposto pela formação escolhida, por mera curiosidade ou por interesse pessoal em aperfeiçoar o conhecimento na área em questão.

Tendo como base a técnica do incidente crítico, os participantes foram orientados a escolher uma situação real para ser relatada. Aproximadamente $61 \%$ dos pós-graduandos relataram experiências ocorridas nos seis dias anteriores à aplicação do questionário, estando 
quase um quarto destes, $14 \%$ do total dos relatos, relacionado a buscas empreendidas no dia anterior à investigação.

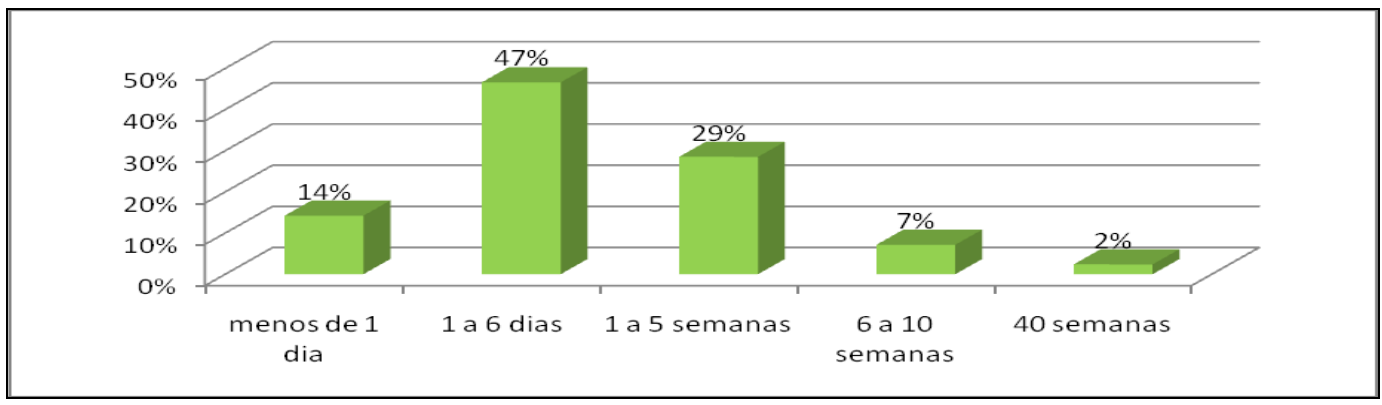

Figura 4 - Quantidade de tempo transcorrida desde a realização da experiência relatada

Com base em experiências empreendidas por Flanagan (1954), nas quais os relatos mais detalhados eram aqueles realizados há menos tempo, pode-se inferir que relatos recentes tendem a ser mais completos e ricos em informações do que aqueles sobre situações ocorridas há um espaço maior de tempo.

Os relatos coletados dizem respeito aos projetos de dissertação ou tese dos pós-graduandos. Praticamente metade dos participantes, $48 \%$ deles, procurou por literatura adicional relacionada a assuntos inseridos em seus projetos. Vinte e nove por centro buscaram conteúdos específicos e previamente conhecidos e, o restante, 23\%, apontaram motivos variados.

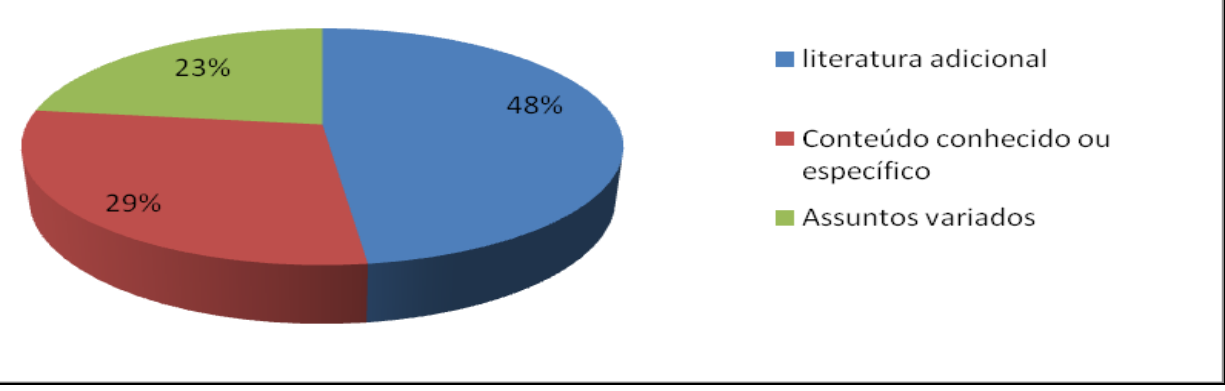

Figura 5 - Material buscado e recuperado na web

Definido o problema que levou à busca, os participantes tomaram a decisão sobre qual ferramenta utilizar. Entre os mestrandos, Google foi a opção de 55,8\% do grupo. Rápido, fácil e prático foram os adjetivos mais atribuídos ao mecanismo. Entre os doutorandos, Google e Google Acadêmico foram mencionados, cada um por 33,33\%. Ao reunir as respostas de ambos os grupos em apenas um gráfico, evidencia-se a preferência pelo Google e pelo Google Acadêmico tanto entre mestrandos quanto entre doutorandos. 


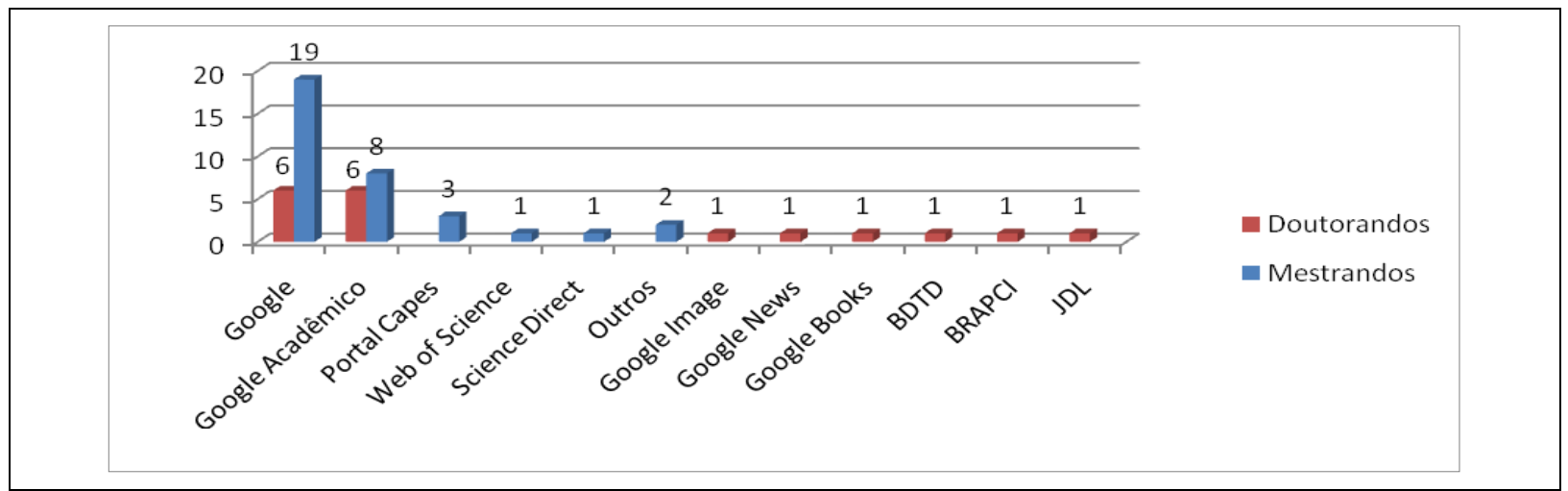

Figura 6 - Mecanismos de busca mais utilizados pelos pós-graduandos

Dos participantes, apenas $13 \%$ utilizaram bancos de dados especializados, vide Figura 7, como a Biblioteca de Teses e Dissertações (BDTD) do Instituto Brasileiro de Informação em Ciência e Tecnologia (IBICT) ou a Base de Dados Referencial de Artigos de Periódicos em Ciência da Informação (BRAPCI), da Universidade Federal do Paraná (UFPR).

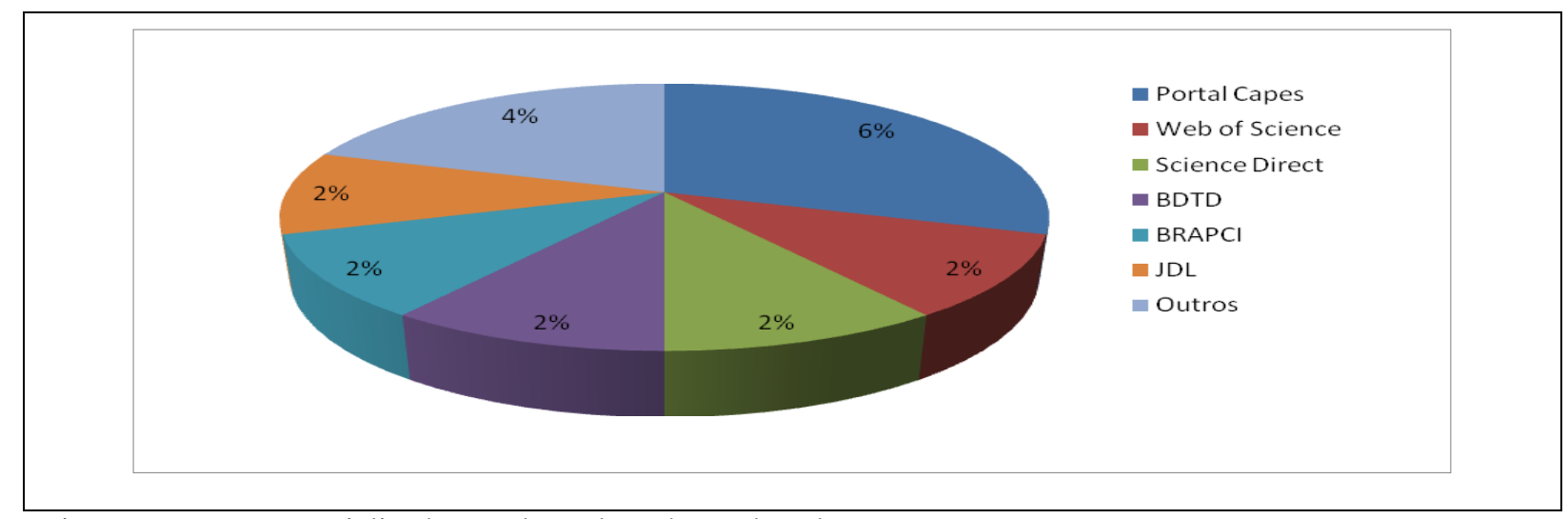

Figura 7 - Bases especializadas usadas pelos pós-graduandos

A conduta dos indivíduos ao buscar informações na web, como constatado em pesquisa semelhante no campo da saúde (IVANITSKAYA; CHES; CASEY, 2006), aponta que baixa porcentagem de consumidores de informação usa recursos avançados em suas buscas, especifica precisamente as palavras-chave ou limita suas buscas de alguma maneira.

Ao relatarem a experiência de busca, 76,4\% dos mestrandos confirmaram utilizar o recurso padrão do mecanismo escolhido, ao invés da opção avançada. Entre os doutorandos, o recurso padrão foi utilizado por $89 \%$ desta população. Doze por cento afirmaram começar a busca sempre pelo recurso padrão para, depois, refinar a busca pesquisando nos resultados obtidos ou fazendo novos cruzamentos de palavras-chave. 
A utilização de recurso avançado, na opinião dos pós-graduandos, aumenta a precisão e filtra de maneira mais efetiva o conteúdo desejado. Além dessa forma de obter resultados melhores, $12 \%$ da população-alvo afirmaram utilizar operadores.

Ao analisar-se como os termos foram inseridos no campo de busca pelos pósgraduandos, observa-se que na prática a utilização dos operadores booleanos mostra-se mais significativa. Ao relatarem suas experiências, $28,8 \%$ dos participantes valeram-se da utilização do operador “+”. Dois por cento utilizaram a forma clássica AND. Outro recurso adotado por $23,1 \%$ da população-alvo foi o emprego de aspas, para definir uma cadeia de expressões e buscar manter a ordem das mesmas.

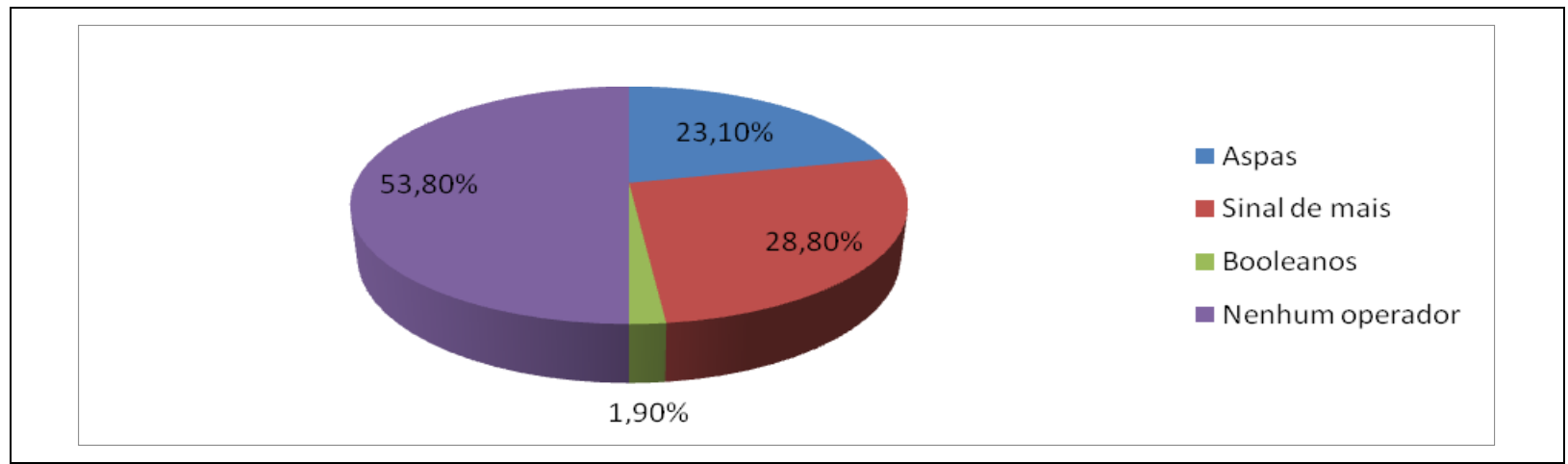

Figura 8 - Utilização de operadores para refinamento da busca

Jansen, Spink e Saracevic (2000, p. 210), em estudo de 1998, registraram que usuários costumam utilizar consultas curtas e empregam o menor esforço possível ao avaliar e refinar suas buscas. Na pesquisa empreendida pelos pesquisadores, mais de 30\% dos usuários utilizaram um único termo na consulta, mas a média de palavras foi de 2,84. Em estudo no mesmo ano, Silverstein et al. (1998 apud YANG, 2005, p. 38) encontraram a média de 2,35. O baixo número de termos, como descrevem os pesquisadores, evidencia dedicação pequena ao processo.

Resultado semelhante foi apontado por Wolfram et al. (2001) ao analisarem mais de 1 milhão de consultas realizadas por 200 mil usuários do site Excite. "Eles descobriram que buscadores na web tendem a colocar pouco esforço tanto na formulação de consultas quanto na avaliação dos resultados, o que confirma padrões reportados em estudos anteriores." (YANG, 2005, p. 39)

Hölscher e Strube (2000, apud YANG, 2005, p. 43), ao investigarem o comportamento de usuários novatos e de usuários experientes, constataram que os segundos exibiram comportamentos muito mais complexos do que os observados na média dos usuários da web. 
Em geral, usuários experientes parecem preferir percorrer um trecho a mais para satisfazer suas necessidades informacionais, o que pode ser percebido com consultas mais longas que o habitual, com média de 3,64 palavras, e a revisão de maior número de resultados.

$\mathrm{Na}$ presente pesquisa, a maior ocorrência foi de consultas formadas por dois termos (43\% do total de participantes), sendo que a média de palavras por consulta ficou em 2,7. Apenas $18 \%$ utilizam mais de quatro termos no campo de busca.

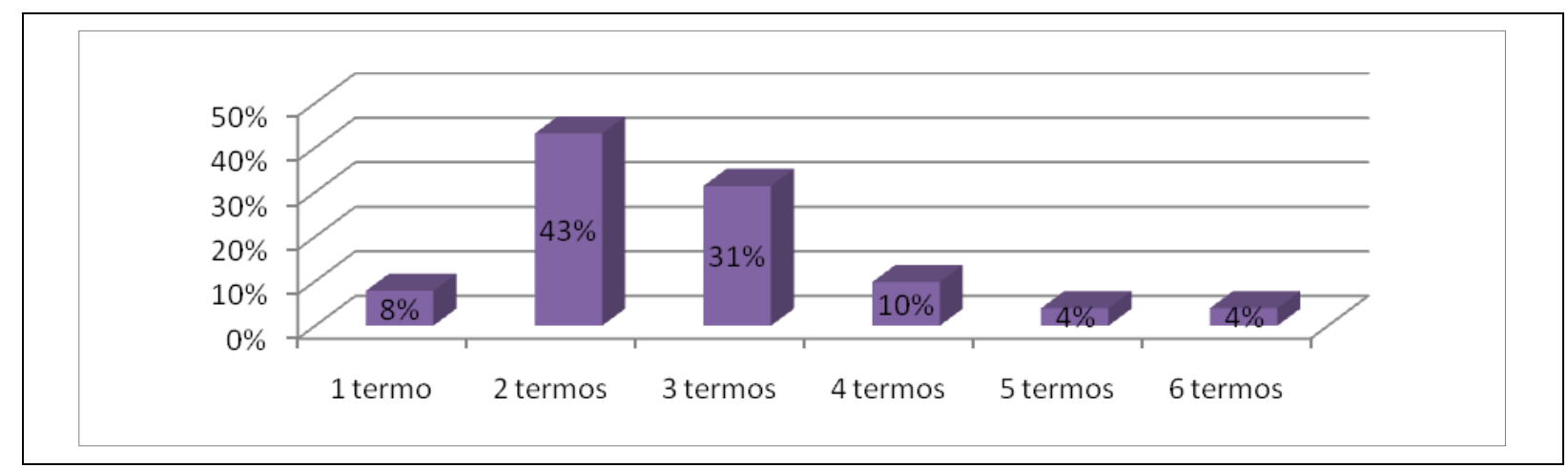

Figura 9 - Número de termos utilizados nas consultas relatadas pelos pós-graduandos

De acordo com as experiências relatadas, as buscas resultaram principalmente em arquivos em formato $p d f$, documentos do Word, slides em Power Point e tabelas produzidas no Excel. Artigos em periódicos e páginas na web aparecem na sequência. Entre os participantes, 42,3\% recuperaram teses e dissertações, assim como livros e citações, ambos encontrados por $34,6 \%$ participantes.

Para filtrar os conteúdos recuperados, os pós-graduandos adotaram diferentes estratégias. As mais repetidas foram a seleção pelos títulos (25\% dos pós-graduandos) e pela observação se o material retornado era artigo acadêmico (13\%).

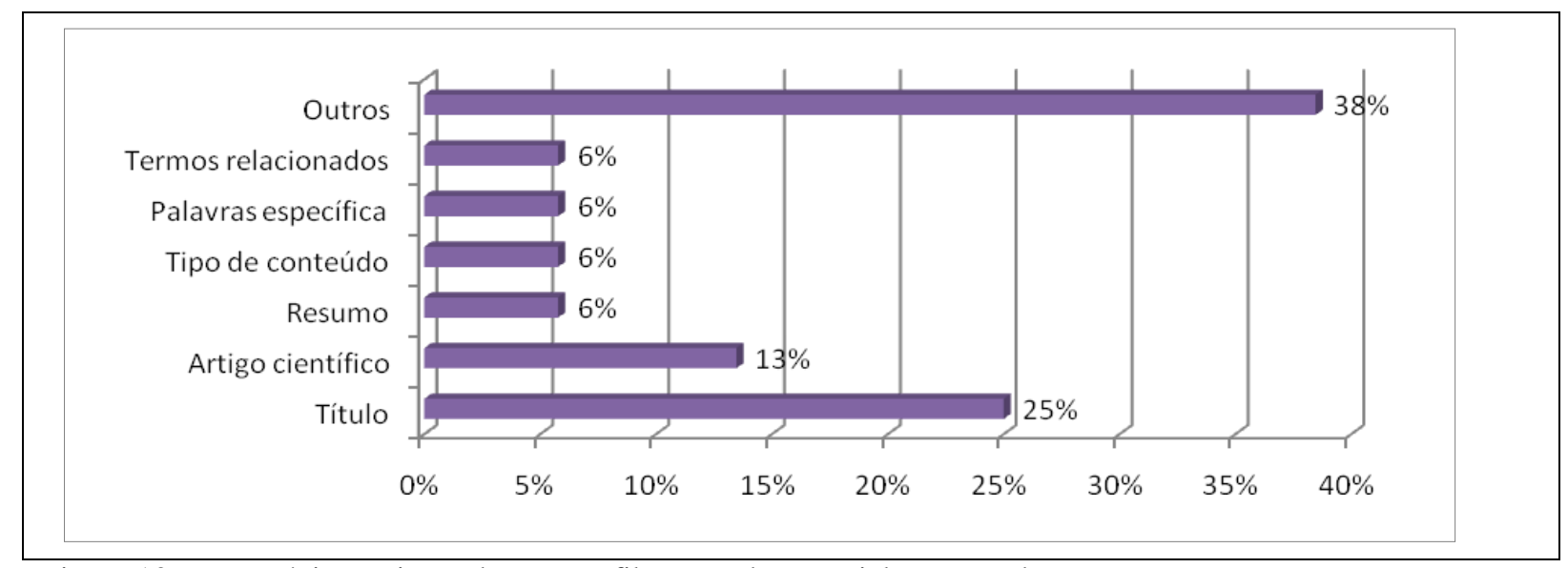

Figura 10 - Estratégias mais usadas para a filtragem do material recuperado 
A escolha de como seria realizada a filtragem dos materiais retornados variou de acordo com o mecanismo utilizado e com o tipo de busca empreendido, mas a análise do título do material recuperado foi a maneira mais frequente de filtragem, independente da base escolhida. O tipo de artigo recuperado também foi decisivo.

$\mathrm{Na}$ avaliação do grau de satisfação com a experiência relatada, 32,3\% dos mestrandos disseram-se completamente satisfeitos com o processo realizado, correspondente ao grau 10 de satisfação, numa escala de 0 a 10 . Entre os doutorandos, apenas $17 \%$ conferiram nota máxima ao grau de satisfação. No resultado geral, porém, os doutorandos mostraram-se mais satisfeitos do que os mestrandos. Considerando-se o somatório dos graus 8, 9 e 10, os mestrandos demonstraram $76,5 \%$ de satisfação, enquanto que os doutorandos somaram $83,3 \%$.

Tanto entre mestrandos quanto entre doutorandos foi obtido alto índice de satisfação, superior a $75 \%$ nos dois grupos em relação aos graus mais elevados da escala, compreendendo o intervalo entre 8 e 10. Se considerarmos o ponto de corte como um grau abaixo, compreendendo o intervalo entre os valor 7 e 10, os resultados de ambos os grupos também se aproximam bastante, correspondendo a $91 \%$ entre os mestrandos e a $89 \%$ entre os doutorandos.

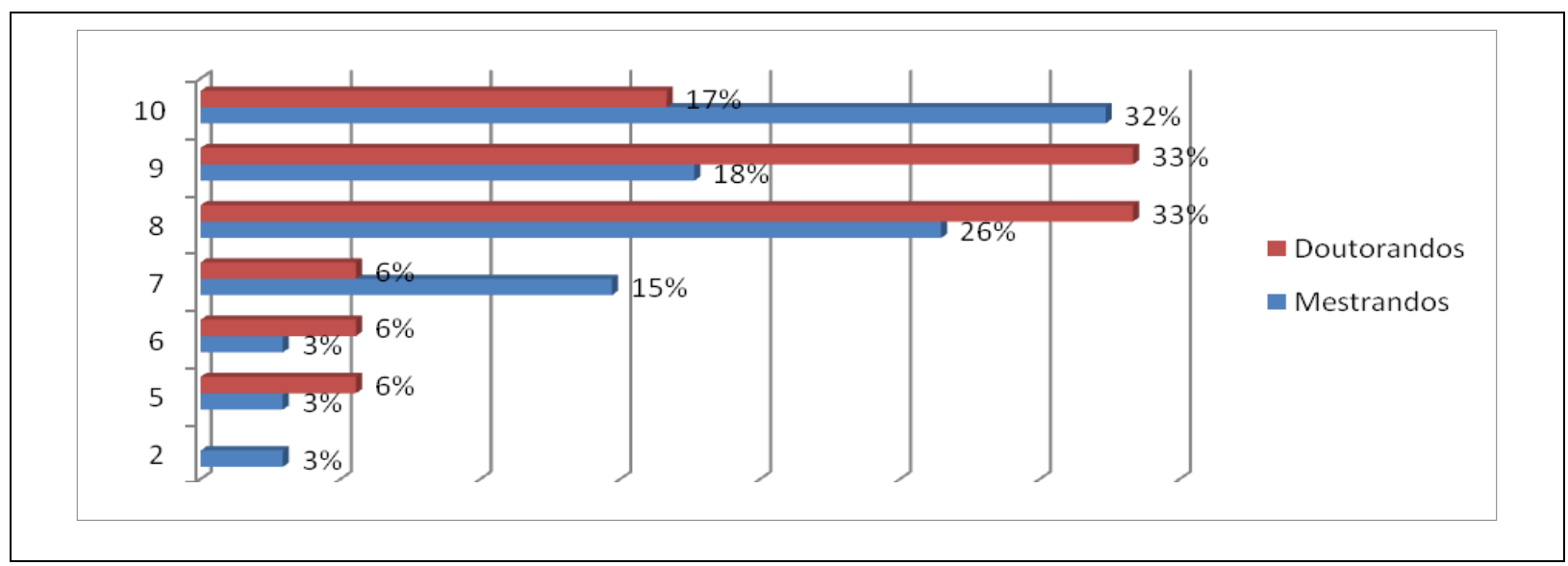

Figura 11 - Grau de satisfação dos pós-graduandos em relação à experiência de busca relatada

Satisfazer o usuário é uma das principais atribuições de um sistema de recuperação da informação - se não a mais importante. Al-Maskari e Sanderson (2010) recorrem a Griffiths et al. (2007) para definir o que se entende por satisfação dos usuários: não é um construto único sobre o qual se baseia a avaliação de eficácia de um sistema, mas algo influenciado por diversos fatores, como saída de dados do sistema, expectativa e atitude do usuário, percepção de facilidade de uso e utilidade do sistema, tipo de sistema e dificuldades de executar uma tarefa. 
Os resultados obtidos por Al-Maskari e Sanderson apontam relação entre satisfação do usuário e efetividade do sistema, mas não de forma incisiva. Quanto maior o número de documentos relevantes obtidos, maior o grau de satisfação do usuário. Também foi constatado que quanto menor o tempo gasto na busca, maior a satisfação do usuário. Já quando se trata do esforço empreendido em relação à satisfação, o impacto é o inverso. Quanto mais esforço, menor a satisfação do usuário.

Em uma tentativa de medir a capacidade de buscar e recuperar informação na web dos pós-graduandos sugeriu-se duas autoavaliações. A primeira precedia o relato da experiência vivenciada em uma busca na web. Já a segunda foi realizada ao final do questionário.

$\mathrm{Na}$ primeira autoavaliação, as notas conferidas pelos pós-graduandos para sua competência variaram de 5 a 10, sendo que a nota 8 foi a mais frequente, tanto entre mestrandos quanto entre doutorandos. Entre os doutorandos, a nota 7 ocorreu mais vezes, ocupando o segundo lugar na autoavaliação, seguida da nota 9, indicando uma maior concentração na faixa situada entre 7 e 9, em comparação com os mestrandos, cuja distribuição é mais diluída entre os diferentes graus autoatribuídos, à exceção da nota 8 .

Coincidentemente, a soma dos resultados para as notas 8,9 e 10, conferidas tanto por mestrandos quanto por doutorandos, resulta em 61\%. A maior parte dos pós-graduandos concedeu-se nota superior a 7. No grupo dos mestrandos, a média de autoavaliação corresponde a 7,5, enquanto que para os doutorandos equivale a 7,7.

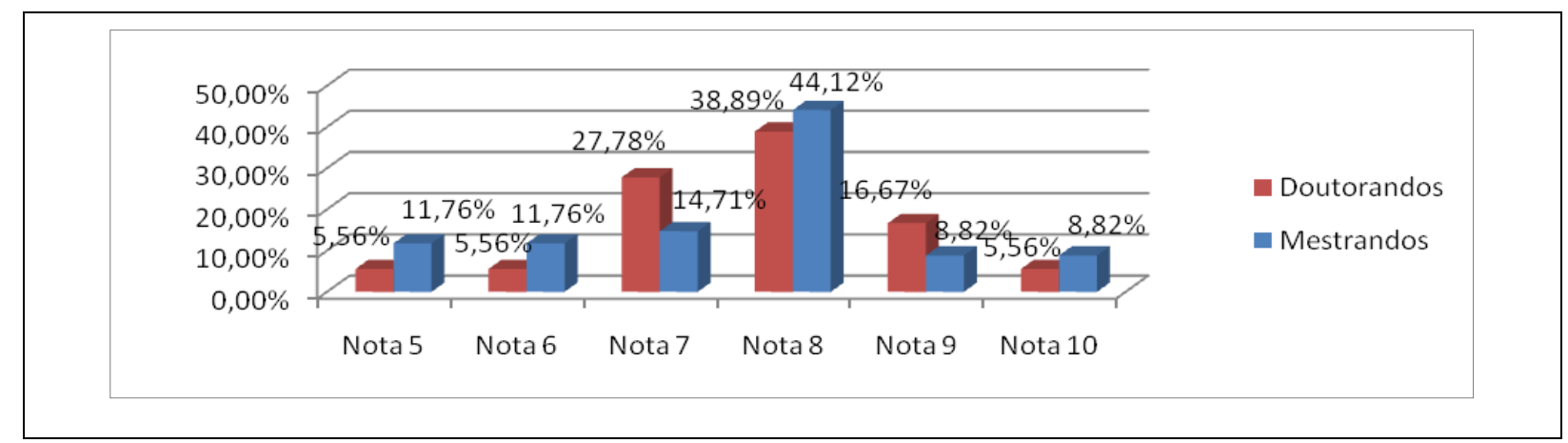

Figura 12 - Autoavaliação da capacidade de buscar e recuperar informações na web - primeira etapa

A segunda autoavaliação, após o relato de uma experiência de busca, teve como objetivo estimular a reflexão sobre o processo recém-realizado e incentivar o exercício de metacognição. De acordo com Ribeiro (2003, p. 110), a metacognição diz respeito, entre outras coisas, ao conhecimento do próprio conhecimento, à avaliação, à regulação e à organização dos próprios processos cognitivos. 


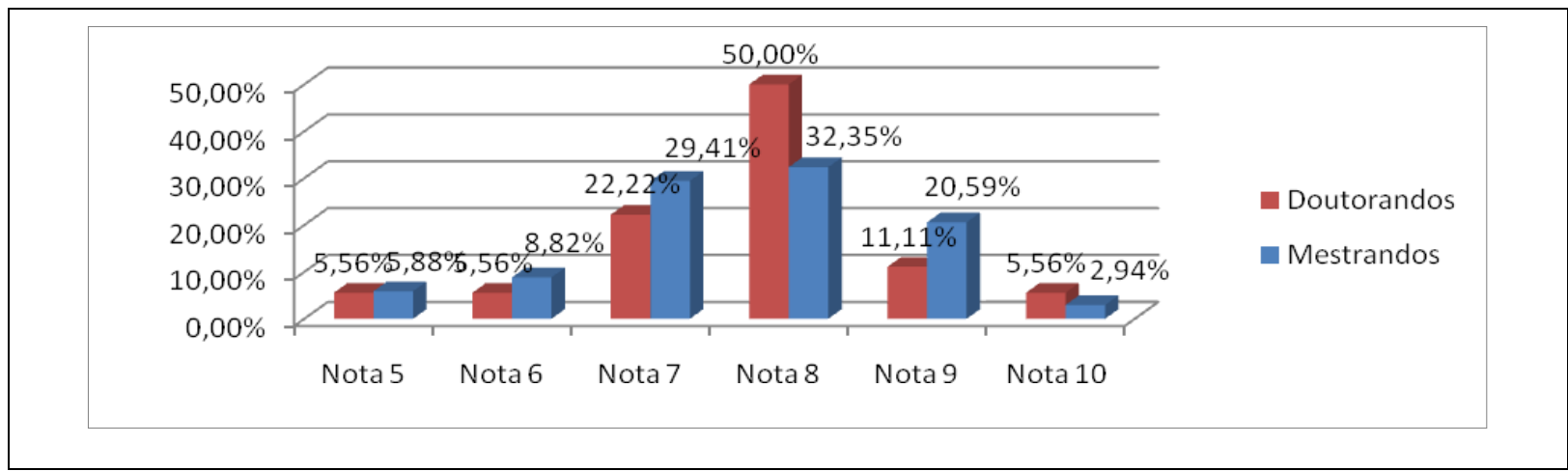

Figura 12 - Autoavaliação da capacidade de buscar e recuperar informações na web - segunda etapa

Os dados demonstram que as autoavaliações permanecem no intervalo compreendido entre as notas 5 e 10, para ambos os grupos, mestrandos e doutorandos. Constatou-se que dos doutorandos, 61,1\% não alteraram a avaliação. Entre os mestrandos, o mesmo ocorreu com $58,8 \%$. Enquanto que entre os doutorandos, $22,2 \%$ aumentaram a nota contra $16,7 \%$ que a diminuíram, entre os mestrandos, 20,58\% cresceram-na e 20,6\% a reduziram em um ponto. Diferente do que ocorreu na primeira avaliação, quando tanto mestrandos quanto doutorandos apresentavam notas superiores a 7, empatando em $61 \%$ na totalização das avaliações compreendidas entre 8 e 10, nesta segunda avaliação mais doutorandos apareceram com nota igual ou superior a $8(66,7 \%)$.

Durante as entrevistas foram apuradas algumas das razões que levaram os pósgraduandos a alterar a nota. Uma mestranda, que havia inicialmente se autoavaliado com nota 8 e modificou a avaliação para 7, justifica dizendo que a alteração ocorreu após a análise do desempenho ao responder ao questionário. Em rápida reflexão, a pós-graduanda avaliou que não encontra muito do que procura na web e demora tempo demais quando consegue recuperar a informação desejada. Outros participantes baixaram a nota por acreditar que, apesar de dominar as técnicas de busca, sempre há algo a ser melhorado. Já um mestrando que aumentou em um ponto sua nota na segunda avaliação justificou que ao longo dos processos de busca que desenvolve descobriu 'macetes' que melhoraram sua atuação.

Andretta et al. (2010, p. 12) concluem que o indivíduo experimenta estratégias de aprendizagem desde criança, tendendo sempre a repetir aquela com a qual obteve maior eficácia. Assim, cada um tem uma estratégia que funciona melhor para si; o processo metacognitivo é diferente para cada um. Quanto melhor a capacidade metacognitiva, melhores as habilidades de aprendizagem, sendo possível aperfeiçoar o tempo e a qualidade do estudo. 


\section{Considerações finais e perspectivas}

Na presente pesquisa, observa-se a importância da reflexão e do raciocínio ao iniciarse um processo de busca e recuperação da informação na web. Quando maior a ponderação sobre a estratégia mais adequada em cada etapa do processo, melhor o aproveitamento. A necessidade de se garantir um aprimoramento contínuo da qualidade em um universo profissional é uma marca da contemporaneidade. Essa dimensão torna-se ainda mais premente em ambientes de atividades que se fundamentam em planejamento investigativo dos procedimentos e capacitação no tratamento da informação, como na esfera da investigação científica. Particularmente, no âmbito de áreas intensivas em conhecimento, o aprimoramento desses processos de tratamento da informação se torna ainda mais relevante e urgente.

Ainda que se trate este de um estudo exploratório, cujo potencial de generalização apresenta limites, o comportamento observado, por meio dos exemplos coletados, demonstra, de modo geral, pouca atividade de planejamento e de reflexão, tanto prévia quanto ao longo dos processos de busca e recuperação da informação científica relatados pela população-alvo.

Diferente da análise de um grupo envolvido em uma pesquisa do dia a dia, a observação da experiência de busca de pós-graduandos em Ciência da Informação induz à perspectiva de comportamentos mais complexos e elaborados. A população-alvo da presente pesquisa de campo está envolvida em uma busca que abarca interpretação dos resultados e processo cognitivo. Em especial, quando se trata de ampliação de um conhecimento, como no caso estudado, espera-se do grupo envolvido julgamentos qualitativos, análise efetiva do material recuperado e que os resultados sejam avaliados criticamente antes de serem absorvidos.

Coerentes com a especificação de que deveriam relatar uma experiência relacionada ao desenvolvimento do projeto de mestrado ou de doutorado, mais da metade dos pósgraduandos informaram estar à procura de literatura relacionada aos assuntos de suas futuras dissertações e teses. Pela natureza desta busca, ela difere-se das tantas realizadas cotidianamente. Deve o usuário então dissociar a prática de busca mais simplificada, do dia-a-dia, desta busca especializada. Ao decidir procurar por informações na web e não em outro repositório, seja uma biblioteca ou uma base de dados off-line, o usuário pode aumentar a qualidade do processo ao refletir sobre como a consulta deverá ser construída, quais os termos mais apropriados, o uso de recursos para refinamento da busca e onde, em que sistemas de informação e bases de dados, ela será melhor realizada, para ampliar sua efetividade e eficiência.

InCID: R. Ci. Inf. e Doc., Ribeirão Preto, v. 3, n.1, p. 125-145, jan./jun. 2012. 
Dos buscadores na web mais utilizados, Google foi o preferido de 55,9\% dos mestrados e $33,3 \%$ dos doutorandos, sendo o mecanismo de busca mais utilizado. Em seguida, Google Acadêmico, com adesão de 23,5\% dos mestrandos e 33,3\% dos doutorandos. Em terceiro lugar, mas somente entre os mestrandos (8,8\% deles), encontrou-se o Portal de Periódicos Capes. Infere-se que o hábito de abrir o buscador mais popular para procurar qualquer tipo de conteúdo não seja deixado de lado, por boa parcela de usuários, nem quando o assunto buscado exige refinamento nas respostas. Apesar de a experiência relatada pelos pós-graduandos caracterizar-se pela busca de informações científicas, a serem usadas em nível acadêmico, rigoroso por natureza, notou-se relativa baixa preocupação na escolha dos locais onde fontes confiáveis poderiam ser localizadas.

Tratando-se de busca por material acadêmico, a escolha da base de dados mais adequada mostra-se como essencial para a recuperação de documentos que tenham valor científico e possam ser usados nesse tipo de trabalho. Há casos, certamente, em que a utilização de um mecanismo de busca mais abrangente se justifique. No entanto, o ponto a ser ressaltado é precisamente que seja justificável em função de sua adequação aos propósitos almejados, e não por sua prevalência ou popularidade de uso. Desta forma, a pesquisa contribui para apontar que em determinadas experiências relatadas pode-se constatar julgamentos equivocados na escolha da base utilizada, o que contribuiu para levar a resultados de menor qualidade e/ou que determinaram esforço adicional para completude satisfatória.

A questão principal, porém, não é o mecanismo de busca escolhido, mas sim a falta de julgamentos qualitativos sobre o processo como um todo. A decisão pela utilização do recurso padrão ao invés do recurso avançado de um mecanismo de busca é exemplo disso. Mais de 75\% dos participantes julgaram o recurso padrão como mais apropriado. Também nota-se o baixo uso de operadores que poderiam facilitar e ampliar a qualidade dos resultados, como os booleanos ou mesmo as aspas.

A partir dessas observações, infere-se que nas buscas empreendidas por grande parte dos pós-graduandos parece preponderar a lei do menor esforço, em detrimento de outros princípios que garantam maior efetividade e eficiência - paradoxalmente levando a um maior esforço posterior ao exercício da busca e, consequentemente, ao processo de busca e recuperação como um todo.

Pós-graduandos que demonstraram maior empenho ao longo das fases de busca obtiveram resultados mais consistentes não apenas ao final, mas durante o processo. Observou-se 
esse comprometimento em diferentes etapas do processo, tal como na tomada de decisão sobre a base mais apropriada, na elaboração cuidadosa da consulta, inclusive com a utilização de recursos que contribuem para maior precisão, e na escolha dos parâmetros para a filtragem dos resultados. Todavia, na maior parte das experiências relatadas foram detectados problemas nas diferentes fases do processo, os quais levaram a dificuldades comuns a diversos participantes. $\mathrm{O}$ excesso de resultados e a dificuldade em encontrar material relevante entre os conteúdos recuperados denotam, novamente, a baixa reflexão ao longo do processo.

Observou-se ainda no estudo que o grau de satisfação dos participantes é alto, mesmo quando são citados percalços ao longo do processo. Entre os mestrandos, $76 \%$ dos participantes pontuaram o grau de satisfação com nota igual ou superior a 8. Entre os doutorandos, esse comportamento chegou a $83 \%$ dos participantes. Acrescentando-se aqui as dificuldades relatadas, dados como esses podem levar à hipótese nada alentadora de que independentemente do que for recuperado, o usuário estará satisfeito. Essa constatação induz a pensar que uma parcela da população-alvo pode ter níveis abaixo do esperado em termos de competência em informação. Entre os aspectos que identificam uma pessoa informacionalmente letrada estão as habilidades para desenvolver estratégias de pesquisa bem-sucedidas e a utilização da informação recuperada de forma crítica.

Com base nas pesquisas referenciadas anteriormente, o comportamento da populaçãoalvo da presente pesquisa poderia ser considerado próximo ao de outros indivíduos pesquisados. Porém, não se deve não perder de vista, o grupo ao qual pertencem os participantes desta pesquisa de campo. Apesar de se tratar de profissionais oriundos de diferentes campos do conhecimento, ao estarem todos inseridos no campo da Ciência da Informação, considerados assim profissionais da informação, aumenta-se a expectativa em relação à postura desses usuários no que diz respeito ao tratamento da informação. A baixa reflexão apontada nesta pesquisa não seria problema fundamental caso a população-alvo estivesse tentando suprir outros tipos de necessidades informacionais.

O usuário é agente essencial na concepção, avaliação, enriquecimento, adaptação, estímulo e funcionamento de qualquer sistema de informação. Por isso, assim como para benefícios próprios, a reflexão deve ser insistentemente estimulada e realizada. Estudos de usuários são importantes para o conhecimento do fluxo de informação científica e técnica, de sua demanda, da satisfação do usuário, dos resultados ou efeitos da informação sobre o conhe- 
cimento, do aperfeiçoamento dos processos, das relações com o conhecimento, da distribuição de recursos de sistemas de informação e de tantos outros aspectos relacionados à informação.

Somente assim, tanto os resultados recuperados com maior qualidade poderão trazer maior satisfação e benefícios aos usuários quanto permitirão estimular melhorias significativas nos próprios sistemas existentes. Dentro desse contexto, com a presente pesquisa espera-se estimular a reflexão não apenas em relação ao grupo populacional estudado, mas a todos aqueles usuários que buscam o aperfeiçoamento constante do seu conhecimento, da sua prática e da sua vida na sociedade.

\section{Referências}

AL-MASKARI, A.; SANDERSON, M. A review of factors influencing user satisfaction in information retrieval. Journal of the American Society for Information (JASIS), v. 61, n. 5, p. 859-868, 2010. Disponível em:

<http://www.seg.rmit.edu.au/mark/publications/my_papers/2010_JASIST_Azzah.pdf>. Acesso em: 10 jul. 2011.

ANDRETTA, I; SILVA, J. G.; SUSIN, N.; FREIRE, S. D. Metacognição e aprendizagem: como se relacionam? Psico, Porto Alegre, v. 41, n. 1, p. 7-13, jan./mar. 2010. Disponível em: $<$ http://revistaseletronicas.pucrs.br/ojs/index.php/revistapsico/article/view/3879>. Acesso em: 10 jul. 2011.

BRODY, T.; SWISHER, N. Digital literacy: a neglected skill? - Interview with Paul Gilster. ESL-Globe, Raleigh, v. 7, n. 1, 2010. Disponível em: <http://www.ncsu.edu/eslglobe/gilster.html>. Acesso em: 3 jan. 2011.

DUDZIAK, E. A. Information literacy: princípios, filosofia e prática. Ciência da Informação, Brasília, v. 32, n. 1, p. 23-35, maio 2003. Disponível em: <http://revista.ibict.br/ciinf/index.php/ciinf/article/view/123>. Acesso em: 20 mai. 2010.

FLANAGAN, J. C. The critical incident technique. Psychological Bulletin, v. 51, n. 4, p. 327-358, 1954. Disponível em: 〈http://www.apa.org/pubs/databases/psycinfo/cit-article.pdf>. Acesso em: 20 mai. 2010.

FOSKETT, D. J. Informática. In: GOMES, H. E. (Org.) Ciência da Informação ou informática? Rio de Janeiro, Calunga, 1980. p. 53-69. Publicado originalmente no Journal of Documentation, v. 26, n.4, p. 340-67, dec. 1970.

GASKELL, G. Entrevistas individuais e grupais. In: BAUER, M. W.; GASKELL, G. Pesquisa qualitativa com texto, imagem e som: um manual prático. 7. ed. Petrópolis: Vozes, 2008. Cap. 3, p. 64-89.

HATSCHBACH, M. H. L. Information literacy: aspectos conceituais e iniciativas em ambiente digital para o estudante de nível superior. 2002. 109 f. Dissertação (Mestrado em 
Ciência da Informação) - IBICT-UFRJ/ECO, Rio de Janeiro, 2002. Disponível em: <http://ibict.phlnet.com.br/anexos/mariahelena2002.pdf>. Acesso em: 10 jul. 2011.

IVANITSKAYA, L.; O’BOYLE, I.; CASEY, A. M. Health information literacy and competencies of information age students: results from the interactive online research readiness relf-assessment (RRSA). Journal of Medical Internet Research, v. 8, n. 2, p. 117, abr./jun. 2006.

JANSEN, B; SPINK, A; SARACEVIC, T. Real life, real users, and real needs: a study and analysis of user queries on the web. Information Processing and Management, v. 36, n. 2, p. 207-227, 2000.

LAWRENCE, S.; GILES, L. Searching the World Wide Web. Science, v. 280, n. 5360, p. 98 100, abr. 1998.

LESK, M. The seven ages of information retrieval. In: CONFERENCE FOR THE 50TH ANNIVERSARY OF AS WE MAY THINK, 1995, Cambridge. Disponível em:

<http://archive.ifla.org/VI/5/op/udtop5/udtop5.htm>. Acesso em: 10 jul. 2011.

MANNING, C. D.; RAGHAVAN, P.; SCHÜTZE, H. Introduction to information retrieval. Cambridge, Cambridge University Press, 2009. Disponível em:

<http://nlp.stanford.edu/IR-book/pdf/irbookonlinereading.pdf>. Acesso em: 20 Jun. 2010.

MILLER, J. O milênio da inteligência competitiva. Porto Alegre: Bookman, 2002.

MOSTAFA, S. Entrevista: Tefko Saracevic. InCID: Revista Ciência da Informação e Documentação, Ribeirão Preto, v. 1, n. 2, p. 161-167, jul./dez. 2010. Disponível em: 〈http://revistas.ffclrp.usp.br/incid/article/view/37/pdf〉. Acesso em: 10 jul.2011.

SARACEVIC, T. Ciência da Informação: origem, evolução e relações. Perspectivas em Ciência da Informação, Belo Horizonte, v. 1, n. 1, p. 41-62, jan./jun. 1996.

POOL, C. A new digital literacy: a conversation with Paul Gilster. Educational Leadership, v. 55, n. 3, p. 6-11, nov. 1997. Disponível em:

<http://www.namodemello.com.br/pdf/tendencias/tecnolnocurric.pdf>. Acesso em: $10 \mathrm{jul}$. 2011.

RIBEIRO, C. Metacognição: um apoio ao processo de aprendizagem. Psicologia: Reflexão e Crítica, Viseu/Portugal, v.16, n. 1, p. 109-116, 2003. Disponível em:

<http://www.scielo.br/pdf/prc/v16n1/16802.pdf>. Acesso em: 10 jul. 2011.

WOLFRAM, D.; SPINK, A.; JANSEN, J.; SARACEVIC, T. Searching the web: the public and their queries. Journal of the American Society for Information Science (JASIS), v. 52, n. 3, p. 226-234, 2001.

YANG, K. Information retrieval on the web. Annual Review of Information Science and Technology, v. 39, p. 33-80, 2005. Disponível em:

<http://elvis.slis.indiana.edu/kiyang/pubs/Webir_arist.pdf>. Acesso em: 26 jun. 2010. 